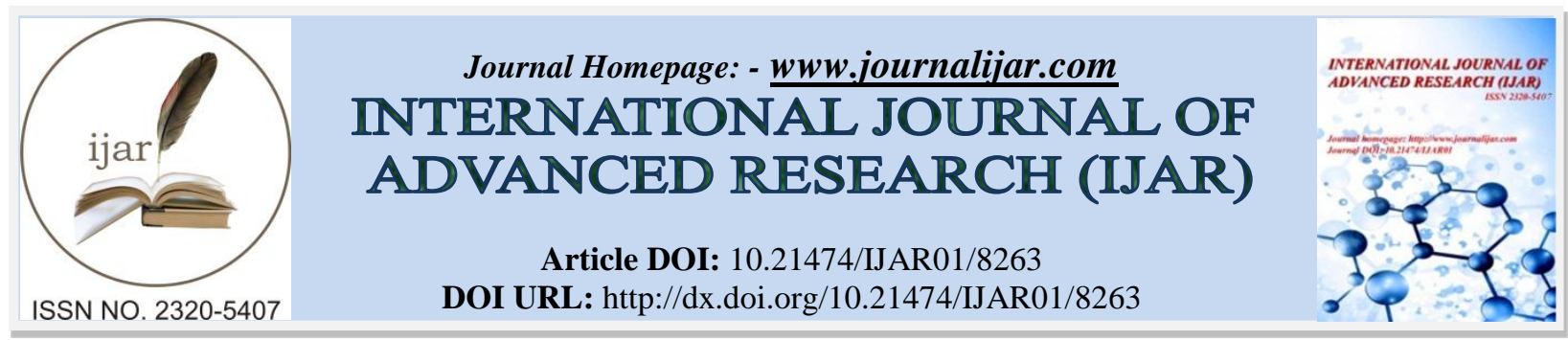

RESEARCH ARTICLE

\title{
PROSTHODONTIC MANAGEMENT OF NEUROLOGICALLY COMPROMISED PATIENTS.
}

\section{Shoma sasidharan ${ }^{1}$, suja joseph ${ }^{1}$, elizabeth $k$ sunny ${ }^{2}$ and veena paul ${ }^{2}$.}

1. Kuzhinjaparampil house. Njakunilam, vallicodu p.o,pathanamthitta.

2. Pushpagiri college of dental sciences, medicity,perumthuruthy, thiruvalla.

\section{Manuscript Info}

Manuscript History

Received: 20 October 2018

Final Accepted: 22 November 2018

Published: December 2018
Abstract

Copy Right, IJAR, 2018,. All rights reserved.

\section{Introduction:-}

Before starting any type of dental treatment a careful examination and anamnesis have to be made. A detailed dental and medical history should be taken to diagnose any metabolic, hormonal, autoimmune, neurological, mental or emotional disorders the patient might suffer from. We should also assess their possible effects and relationship to complaints about previous dentures.

The systemic status of the patient should be evaluated before planning any prosthodontic procedures. Treatment planning is a consideration of all the diagnostic findings, systemic and local which influence the surgical preparations of the mouth, impression making, maxilla-mandibular relation records, occlusion, form and material in the teeth.

So the dentist must always consider the systemic factors in the treatment plan. Systemic diseases have a direct relation to denture success. Many systemic diseases have a local manifestation with no apparent systemic symptoms and others have both local and systemic reactions.

\section{Neurologic Diseases}

Special management considerations are necessary for patients with neurological disease. These include pretreatment treatment planning, therapeutic techniques, and post treatment requirements. Neurologic conditions facing the dentist include abnormalities associated with the cranial nerves, facial sensory loss, facial paralysis, and conditions such as Parkinson disease, epilepsy, multiple sclerosis, stroke, and myasthenia gravis.

\section{Parkinsons Disease}

Parkinson's disease (PD) is a neurodegenerative disorder affecting the adults in middle and late life. It is a long-term degenerative disorder of the central nervous system that mainly affects the motor system. The symptoms generally come on slowly over time[1].This disease is characterized by tremors, slowness of movements (bradykinesia), muscle rigidity, postural instability, gait disturbances.

This disease starts slowly and is unilateral to start with. The early signs of the disease are mild stiffness and resting tremors. There is a typical 'pill- rolling' movement between thumb and fingers the tremors spread to the legs, face, tongue and mandible. These patients show inability to initiate voluntary and involuntary movements (akinesia) and exhibit flexed posture due to rigidity.[2]

Corresponding Author:-Shoma sasidharan.

Address:-Kuzhinjaparampil house. Njakunilam, vallicodu p.o,pathanamthitta. 


\section{Orofacial Findings}

A typical "mask like" appearance due to reduction in the movements of the small facial muscles can be seen. Due to slow chewing movements, reduced tongue movements and difficulty in swallowing need more time to consume food. Drooling of saliva from the corners of the mouth is followed by angular cheilosis. Bruxism, attrition and some cracked teeth are due to the orofacial musculature tremors and levodopa medications. The incidence of dental caries and periodontal diseases is increased due to poor oral hygiene [3]. Burning sensation of the tongue, hard palate, floor of the mouth, lips, cheeks and edentulous alveolar ridge can be seen. Tremor and rigidity of the orofacial musculature may induce orofacial pain, temporomandibular joint discomfort, cracked teeth and dental attrition and may create difficulties in controlling and retaining dentures.[4] Burning sensation of the tongue, hard palate, floor of the mouth, lips, cheeks and edentulous alveolar ridge are noted, whether the patient is dentulous or edentulous, removable denture wearer or dentate subjects[5]

\section{Prosthodontic Management}

The dentist has to consult the patient's physician before starting the treatment. Short appointments of less than 45 minutes should be scheduled for such patients. Patient should empty his/her bladder to prevent urinary urgency and incontinence. In order to prevent orthostatic hypotension the dental chair should be raised slowly so that the patient is adjusted to the upright sitting position [2] . Relaxation and diversion methods can be implemented to reduce the stress. Parkinson's disease patients cannot keep their mouth open, there can be drooling of saliva and tongue and head movement may interfere with the treatment. An extra oral ratchet-type prop or intraoral rubber bite block can be used to keep the mouth open. [6]

\section{Removable Prosthesis}

Due to tremors, rigidity of the orofacial musculatures and drooling of saliva patients find it difficult in controlling and retaining the dentures. Quick setting impression materials should be used in recording impressions. Neutral zone technique, flange technique and selective grinding of the occlusion are useful to obtain the maximum stability and retention. . Moisture based denture adhesives or artificial salivary substitutes can be prescribed.[7] Metal denture base or high impact denture base resin is used to fabricate the denture. The major connectors should not be of smaller design so as to prevent its aspiration and choking. Precision attachments are not advocated due to lack of patient stability. Flexible dentures (valplast), a recently available prosthetic material for removable partial dentures provide good retention and stability. Self cleansing abutments should be used for over dentures.[2]

\section{Fixed Partial Denture}

Supragingival or equigingival margins should be given for the preparations. Full coverage design is preferred for maximum retention and resistance. An expanding vinyl polysiloxane gingival retraction material can be used for retraction of the gingival sulcus. Metal or gold bridge can be advocated in bruxism patients. [8]

\section{Implant Surgery}

The quality of oral health and general health has improved by using dental implant supported prosthesis and is associated with marked increase in masticatory ability.[9] Mandibular over denture with magnetic attachment can be utilized as it is easy for insertion by the patient or by the caregiver.[10] Local anaesthesia with epinephrine must be cautiously administered if the patient is treated with levodopa and entacapone, as it may lead to an increase in blood pressure and heart rate.

\section{Unilateral Facial Paralysis}

Facial paralysis is a condition that affects the muscles of face by involving the VIIth cranial nerve. Some of the clinical features of facial paralysis (LMN) are facial asymmetry, drooping of the corner of mouth, inability to close/wink the eye, loss of wrinkles of forehead, mask-like appearance, and difficulty in speech and eating. In the prosthodontic management of facial paralysis, the general principles of complete denture design are essentially the same; the disorder does affect the design of particular surfaces or parts of denture.[11]

\section{Complete Denture}

The Impressions of the the denture bearing areas are captured with thick borders on the affected side. This is done to support the flaccid musculature. The occlusal plane was oriented parallel to a line joining the angles of the functionally deviated mouth, i.e., canting of occlusal plane was performed.[12] Midline is marked in the centre of the deviated mouth. Anterior teeth are set according to the shifted midline. Zero degree posterior teeth were selected 
in such cases. . Flaccid facial muscles needed support and this was done by adding wax and then acrylizing it. Use of nonanatomic posterior teeth minimizes the damage to the denture supporting tissues.[13]

\section{Stroke}

Neurologic sequalae influencing dentistry occur mainly in patients who have had a middle cerebral or basilar artery accident. Among the characteristic findings of middle cerebral artery accident are contra lateral hemiplegia, sensory or motor deficit or both, agnosia, and aphasia, depending on whether the dominant side is occluded.

\section{Complete denture:}

Patients with a sensory deficit of the soft palate and pharynx have diminished response of the gag reflex to material in that region. This diminished response may cause the aspiration of material. Before inserting the tray the head should be erect. The head should be tilted forwards while the operator holds the tray. When mandibular impressions are being taken cheek muscles are not to be tugged forcibly. Due to the thick ropy saliva of the neurotic or anxious patient, the impression loses its intimate mucosal contact. surface tension reducing mouthwashes are to be used before obtaining the impression.

Flat plane teeth with little or no vertical overjet on the anterior aspect are suggested. Horizontal overjet in posterior and anterior surfaces helps to keep flaccid muscles musculature away from the occlusal surfaces and helps to prevent cheek-biting. Denture functions will be more efficient if the vertical dimension is reduced. When the twelfth cranial nerve is involved the tongue can manipulate the food bolus across the occlusal table more readily when the teeth are closer to the ridge.[14]

\section{Partial Denture}

Patients with hemiplegia often have difficulty in removing the partial denture. Additional clasps should be given on the non affected side. Bracing arms on both sides of the arch compensate partly for lack of retentive clasp arms. Retentive portions of clasps should not go deeply into undercut regions but should be designed to engage the infrabulge region as close to the survey line as possible. Clasps should be fabricated with minimum bulk. Partial lower dentures may have to be constructed non retentive to be removed with the additional aid of tongue pressure. The patient can be trained to use crochet needles, size 5 and larger, to engage the clasp arms in removal of his prosthesis. [15]

\section{Epilepsy}

Epilepsy is a chronic disease that can affect oral health and prosthodontic status in different ways. . The disease may affect the dental status and oral health of patients in a number of ways: The seizures themselves can cause injuries to the teeth and dental prostheses. Patients with epilepsy were shown to have a significantly worse dental status in many respects, supporting the notion that epilepsy has a negative effect on dental status. [16]

Classification of patients with epilepsy according to dental risk factors and dental manageability and recommendations for prosthodontic treatment[17]

\begin{tabular}{|l|l|l|}
\hline GROUP & CRITERIA FOR ENTRANCE & $\begin{array}{l}\text { GUIDELINES PROSTHODONTIC } \\
\text { TREATMENT }\end{array}$ \\
\hline Group I & $\begin{array}{l}\text { Patients who have been seizure } \\
\text { free for years, either with or } \\
\text { without medication. } \\
\text { Patients with rare seizures (less } \\
\text { than once a year) } \\
\text { Patients exclusively with seizures } \\
\text { that do not involve the masticatory } \\
\text { apparatus (absence, myoclonus, } \\
\text { and certain partial seizures) }\end{array}$ & \\
\hline Group II & $\begin{array}{l}\text { Patients with frequent partial } \\
\text { seizures involving the masticatory } \\
\text { apparatus, accompanied by } \\
\text { twitching of facial and masticatory }\end{array}$ & \\
\hline
\end{tabular}




\begin{tabular}{|c|c|c|}
\hline & $\begin{array}{l}\text { muscles or oral automatisms such } \\
\text { as grinding of teeth. Generalized } \\
\text { tonic-clonic seizures, if present, } \\
\text { appear less often than once a year }\end{array}$ & \\
\hline Group III & $\begin{array}{l}\text { Patients with frequent generalized } \\
\text { tonic-clonic seizures, more than } \\
\text { once a year, or other seizures } \\
\text { associated with a fall }\end{array}$ & $\begin{array}{l}\text { Incisal restoration is discouraged Fixed rather than } \\
\text { removable prostheses are preferred } \\
\text { Fixed partial dentures may include additional } \\
\text { abutments Removable partial dentures should be } \\
\text { securely retained For nearly edentulous subjects, } \\
\text { telescopic retention may be advised with denture } \\
\text { bases made of metal or reinforced with metal } \\
\text { For complete dentures, metal base recommended }\end{array}$ \\
\hline
\end{tabular}

Fixed prostheses are preferred over removable partial dentures because of the danger of seizure-related injuries and aspiration. For fixed prosthesis, a nickel-chrome composite material is used more frequently than a metal-ceramic composite material.[18] A metal base is best used to minimize the chances of fracture If a removable denture is unavoidable. Replacement of missing teeth is important to prevent the tongue from being caught in the edentulous spaces during seizures in epileptic patients. Patients in Group I, those that are seizure free or have only seizures without motor phenomena or falls, should receive prosthodontic care that is identical with that of the general population.

Patients in Group II have an increased risk for injury or wear to teeth and prostheses. A slightly increased force on the teeth and dental prostheses are expected in this group, as there are no falls and forceful facial contractions. Use of ceramic inlays is best avoided and complete metal ceramic crowns are used. For fixed partial denture additional abutments is used for better stability. Removable partial dentures are constructed with a large metal base.

\section{Myasthenia Gravis}

Myasthenia gravis (MG) is an autoimmune neuromuscular disorder that presents challenges for both the dental practitioner and the patient. Myasthenia gravis (MG) is an autoimmune neuromuscular disorder that presents challenges for both the dental practitioner and the patient. Facial and masticatory muscles may be involved and complicate dental care and treatment. Exacerbation of muscle weakness and fatigability that characterize this disorder can be precipitated by certain medications used in dentistry. The dental team should be cognizant of the medication precautions in this population, modify dental care to accommodate existing neuromuscular weakness and drug therapy, and be prepared to manage emergent complications occurring in the dental office.

Short-duration morning appointments will minimize fatigue and take advantage of the typically greater muscle strength during the morning hours. Appointments are best scheduled approximately one to two hours following oral anticholinesterase medication so as to benefit from maximum therapeutic effect and decrease the risk of myasthenic weakness or crisis.

The patient's ability to manage complete dentures may be compromised by the inability of the weak muscles to assist in retaining the lower denture and to maintain a peripheral seal for the upper denture. Over extended and over contoured maxillary dentures with thick flanges that impinge upon muscle and frenal attachments can lead to muscle fatigue and altered salivation. Improperly fitting dentures may exacerbate symptoms of difficulty in closing the mouth, tongue fatigue, a tight upper lip, dry mouth, impaired phonation, dysphagia, and masticatory problems.[19]

\section{Conclusion:-}

Caring for the edentulism in older adult patient is a major challenge that the profession faces. . So an older adult's medical, functional and psychological status should be considered in each phase of any prosthetic treatment. The successful management of patient begins right from the medical history to the treatment plan in which much consideration has to be given to the systemic status of individual. The practitioner neglecting the systemic status in the history will step into more serious complication at the cost of individual life. Although dental treatment techniques require little modification, the informed dentist will recognize the need for more information on the identification and management of chronic diseases in this age group. Increased knowledge and concern for the patient should allow better treatment planning and effective patient care management. 


\section{References:-}

1. Rhea A. Prosthodontic Management of a Patient with Parkinson's Disease-A Case Report. Journal of Young Pharmacists. 2018 Jul;8(3):377.

2. Rajeswari CL. Prosthodontic considerations in Parkinson's disease. PJSR. 2010;3:45-7.

3. Friedlander AH, Mahler M, Norman KM, Ettinger RL. Parkinson disease: systemic and orofacial manifestations, medical and dental management. The Journal of the American Dental Association. 2009 Jun 1;140(6):658-69.

4. Dirks SJ, Paunovich ED, Terezhalmy GT, Chiodo LK. The patient with Parkinson's disease. Quintessence international. 2003 May 1;34(5).

5. Clifford TJ, Warsi MJ, Burnett CA, Lamey PJ. Burning mouth in Parkinson's disease sufferers. Gerodontology. 1998 Dec;15(2):73-8.

6. Corah NL, Gale EN, Illig SJ. The use of relaxation and distraction to reduce psychological stress during dental procedures. The Journal of the American Dental Association. 1979 Mar 1;98(3):390-4.

7. Turner M, Jahangiri L, Ship JA. Hyposalivation, xerostomia and the complete denture: a systematic review. The Journal of the American Dental Association. 2008 Feb 1;139(2):146-50.

8. Al Hamad KQ, Azar WZ, Alwaeli HA, Said KN. A clinical study on the effects of cordless and conventional retraction techniques on the gingival and periodontal health. Journal of clinical periodontology. 2008 Dec;35(12):1053-8.

9. Heckmann SM, Heckmann JG, Weber HP. Clinical outcomes of three Parkinson's disease patients treated with mandibular implant overdentures. Clinical oral implants research. 2000 Dec;11(6):566-71.

10. Chu FC, Deng FL, Siu AS, Chow TW. Implant-tissue supported, magnet-retained mandibular overdenture for an edentulous patient with Parkinson's disease: A clinical report. The Journal of prosthetic dentistry. 2004 Mar 1;91(3):219-22.

11. Pandey S, Datta K. Prosthodontic management of a completely edentulous patient with unilateral facial paralysis. The Journal of Indian Prosthodontic Society. 2007 Oct 1;7(4):211.

12. Larsen SJ, Carter JF, Abrahamian HA. Prosthetic support for unilateral facial paralysis. The Journal of Prosthetic Dentistry. 1976 Feb 1;35(2):192-201.

13. Pandey S, Datta K. Prosthodontic management of a completely edentulous patient with unilateral facial paralysis. The Journal of Indian Prosthodontic Society. 2007 Oct 1;7(4):211.

14. Zafran JN, Zayon GM. Prosthodontics and the stroke patient. The Journal of the American Dental Association. 1967 May 1;74(6):1250-4.

15. Nagle RJ, Sears VH. Dental prosthetics; complete dentures. Mosby; 1958.

16. Buck D, Baker GA, Jacoby A, Smith DF, Chadwick DW. Patients' experiences of injury as a result of epilepsy. Epilepsia. 1997 Apr;38(4):439-44.

17. Prosthodontic status and recommended care of patients with epilepsy Katalin Karolyhazy, DDS,a Peter Kivovics, DDS, PhD,b Pal Fejerdy, DDS, PhD,c and Zsuzsanna Aranyi, MD, PhDd Semmelweis University, Budapest, Hungary

18. Mehmet Y, Senem Ö, Sülün T, Hümeyra K. Management of epileptic patients in dentistry. Surgical Science. 2012 Jan 13;3(01):47.

19. AlHelal A, Jekki R, Richardson PM, Kattadiyil MT. Application of digital technology in the prosthodontic management of a patient with myasthenia gravis: A clinical report. The Journal of prosthetic dentistry. 2016 May 1;115(5):531-6. 